\title{
Recombination in men with Klinefelter syndrome
}

\author{
Joanna Gonsalves 1,2,3,4,5, Paul J Turek ${ }^{5}$, Peter N Schlegel ${ }^{6,7}$, Carin V Hopps ${ }^{6,7}$, \\ Jingly Fung Weier ${ }^{1}$ and Renee A Reijo Pera ${ }^{1,2,3,4,5}$
}

${ }^{1}$ Department of Physiology, Programs in Human Genetics, Cancer Genetics, and Developmental and Stem Cell Biology, University of California at San Francisco, 513 Parnassus Avenue, San Francisco, CA 94143-0556, USA,

${ }^{2}$ Program in Human Embryonic Stem Cell Biology, University of California at San Francisco, 513 Parnassus Avenue, San Francisco, CA 94143-0556, USA, ${ }^{3}$ Center for Reproductive Sciences, University of California at San Francisco, 513 Parnassus Avenue, San Francisco, CA 94143-0556, USA, ${ }^{4}$ Department of Obstetrics, Gynecology and Reproductive Sciences, University of California at San Francisco, 513 Parnassus Avenue, San Francisco, CA 94143-0556, USA, ${ }^{5}$ Department of Urology, University of California at San Francisco, 513 Parnassus Avenue, San Francisco, CA 94143-0556, USA, ${ }^{6}$ Department of Urology, Weill Medical College of Cornell University, 525 East 68th Street, New York, NY 10021, USA and ${ }^{7}$ Center for Biomedical Research, The Population Council, New York, NY 10021, USA

Correspondence should be addressed to P J Turek; Email: pturek@urol.ucsf.edu

\begin{abstract}
Klinefelter syndrome (KS: 47,XXY), occurs in one in 1000 male births. Men with KS are infertile and have higher rates of aneuploidies in sperm compared with normal fertile men. In the course of analyzing recombination in a population of infertile men, we observed that four men in our study presented with KS. We examined whether these men differed in recombination parameters among themselves and relative to normal men. Even though the number of men with KS analyzed was small, we observed remarkable variation in spermatogenesis. In spite of the fact that the men had the same genetic cause for infertility, two of four KS patients had few or no spermatogenic cells that progressed through meiosis to the pachytene stage, whereas the other two men produced abundant pachytene cells that had recombination frequencies comparable with those of fertile men, although one had a significant reduction in fidelity of synapsis. Moreover, regardless of histological appearance, examination of outcomes of assisted reproduction indicated that sperm were extracted from testis biopsies in all four cases, and when used in assisted reproductive practices chromosomally normal babies were born. These results reinforce that: (i) men with the same underlying genetic cause for infertility do not present with uniform pathology, (ii) the checkpoint machinery that might arrest spermatogenesis in the face of chromosomal abnormalities does not prevent pockets of complete spermatogenesis in men with KS, and (iii) aneuploidy, in some cases, is compatible with birth of a chromosomally normal child, suggesting that sperm produced from a background of aneuploidy can be normal in men with KS.
\end{abstract}

Reproduction (2005) 130 223-229

\section{Introduction}

Meiosis is a well-conserved process of DNA replication followed by two cell divisions to generate haploid gametes. Aneuploidy arises in meiosis I or II by nondisjunction and is a rare event in most organisms. For example, rates of aneuploidy in meiotic cells have been reported as 1/10 000 cells for Saccharomyces cerevisiae, 1/6000 for Drosophila melanogaster and approximately $1 / 100$ to $1 / 200$ for mice (Hassold \& Hunt 2001). Surprisingly, the rate of aneuploidy in humans may be as high as $1 / 10$ to $1 / 30$, depending on factors such as age and sex (Hassold \& Hunt 2001). Aneuploidy is detected in approximately $5 \%$ of clinically recognized pregnancies. However, in general, most aneuploidies are eliminated early in gestation. Less than $1 \%$ of newborns are trisomic, and clearly sex chromosome trisomies are less severe than those of autosomes (Thomas \& Hassold 2003). Although maternal errors account for more than $95 \%$ of autosomal trisomies, it is notable that paternal errors account for $50 \%$ of cases of Klinefelter syndrome (KS: 47,XXY) (Simpson et al. 2003).

KS occurs in 1 of every 1000 male births and is characterized by several features including infertility, typically azoospermia (no sperm in the semen), small testes and penis, Leydig cell hyperplasia, androgen deficiency, abnormally long limbs, sparse or absent facial, pubic or body hair, feminine distribution of adipose tissue, and increased frequencies of autoimmune disorders and learning disabilities (Smyth \& Bremner 1998, Simpson et al. 
2003). It is reported that men with KS also have higher rates of sex chromosomal aneuploidy ranging from 0.1 to $50 \%$ and autosomal aneuploidy (of chromosomes 13, 18 and 21) in their sperm compared with normal fertile men (Moosani et al. 1995, Martini et al. 1996, Guttenbach et al. 1997a, Estop et al. 1998, Foresta et al. 1998, Kruse et al. 1998, Aran et al. 1999, Lim et al. 1999, Okada et al. 1999, Rives et al. 2000, Hennebicq et al. 2001, Levron et al. 2001, Morel et al. 2003, Simpson et al., 2003), an observation paralleled by studies in 41, XXY mice (Mroz et al. 1999). It is also well established that spermatogenesis in male $X X Y$ mice generally arrests prior to the onset of meiosis (Lue et al. 2001). Production of spermatids may be a result of rare patches of breakthrough spermatogenesis in which germ cells may survive and progress through meiosis (Lue et al. 2001). Thus, XXY mice have abundant Sertoli and Leydig cells but few or no germ cells in the spermatogenic tubules; moreover, aneuploidies of both autosomal and sex chromosomes are increased in XXY mice (Mroz et al. 1999).

Due to the higher rates of both autosomal and sex chromosomal aneuploidy found in sperm of men with KS, we hypothesized that these men may have altered recombination parameters compared with normal fertile men. Reagents that mark sites of recombination can be used to analyze recombination frequencies in human spermatocytes (Barlow \& Hulten 1998, Lynn et al. 2002). Antibodies that localize to sites of recombination and to the synaptonemal complex (SC) allow the quantification of recombination events per meiotic pachytene cell and the analysis of synapsis fidelity. We recently reported that men with few or no sperm had reduced recombination frequencies (Gonsalves et al. 2004). In addition, recent case reports identified an infertile man who had a complete arrest in meiosis associated with failure to form the SC, and a man with non-obstructive azoospermia with reduced recombination frequency and discontinuities in the SC (Judis et al. 2004, Sun et al. 2004). Thus, the tools to examine recombination in single spermatocytes are now available and substantial evidence suggests that men with different phenotypes have altered recombination. In this study, we directly compared recombination frequencies and synapsis fidelity in men with KS with those of fertile men with normal spermatogenesis; we then examined the results of ART (assisted reproductive techniques).

\section{Materials and Methods}

\section{Tissue collection}

Informed consent for collection of tissues was obtained from patients presenting for treatment of male infertility at Cornell University Medical Center and at the University of California at San Francisco, as appropriate. All of the procedures were in accordance with the responsible committee on human research and with the Helsinki Declaration of 1975, as revised in 1983. In most cases, one-third of each sample was processed immediately for meiotic analysis, another third was preserved individually at $-80^{\circ} \mathrm{C}$ for molecular analysis and the remainder was fixed in Bouin's fixative for histological analysis.

\section{Meiotic analysis}

Testis tissue was processed as previously reported (Barlow \& Hulten 1998, Lynn et al. 2002, Gonsalves et al. 2004). Primary antibodies used were: human anti-CREST (gift from Bill Brinkley, Baylor College of Medicine), mouse anti-mutL homolog 1 (MLH1) (Oncogene, La Jolla, CA, USA) and rabbit anti-rat SC protein 3 (SCP3) (gift from Christa Heyting, Wageningen University). The CREST antibody localizes to the centromere, the MLH1 antibody localizes to recombination foci and the SCP3 antibody marks the lateral element of the SC. For secondary antibodies, AMCAlabeled donkey anti-human (Jackson ImmunoResearch, Westgrove, PA, USA), FITC-labeled donkey anti-rabbit (Jackson ImmunoResearch), and rhodamine-labeled donkey anti-mouse (Jackson ImmunoResearch) were used. Slides were scanned with a Fluorescent Leica DMRB microscope and images of SCs, MLH1 and CREST locations were captured on a Leica DFC 300F camera. Prints of captured images were analyzed in order to determine the number of MLH1 foci on each individual SC in the whole cell and also to determine fidelity of chromosomal synapsis.

\section{Fluorescence in situ hybridization (FISH)}

FISH was done on slides that were prepared for meiotic analysis and stored at $-80^{\circ} \mathrm{C}$. DNA probes chosen to bind specifically to chromosome $X$ (CEP $X$ SpectrumOrange), chromosome $\mathrm{Y}$ (CEP Y SpectrumGreen) or chromosome 18 (CEP 16 SpectrumAqua) were from Vysis Inc. (Downers Grove, IL, USA). Hybridization was according to manufacturer's protocol using $1 \mu \mathrm{l}$ probe per $10 \mu \mathrm{l}$ hybridization mixture.

Slides were incubated in Carnoy's fixative (methanolacetic acid, 3:1, vol/vol), $10 \mathrm{~min}$, followed by immersion in $2 \times \operatorname{SSC}\left(0.3 \mathrm{M} \mathrm{NaCl}, 0.03 \mathrm{M} \mathrm{Na}_{3}\right.$ citrate $\left.2 \mathrm{H}_{2} \mathrm{O}, \mathrm{pH} 7.0\right)$, $5 \mathrm{~min}, 20^{\circ} \mathrm{C}$. Slides were pretreated with $25 \mu \mathrm{g} / \mathrm{ml}$ pepsin (Amresco, Solon, $\mathrm{OH}, \mathrm{USA}$ ) in $0.01 \mathrm{M} \mathrm{HCl}, 10 \mathrm{~min}$ at $37^{\circ} \mathrm{C}$, and immersed in PBS, $5 \mathrm{~min}$. Then, slides were incubated in $1 \%$ paraformaldehyde/PBS, $5 \mathrm{~min}, \mathrm{PBS}, 5 \mathrm{~min}$, and sequential changes of ethanol and air dried. Slides and hybridization mixture were denatured, $8 \mathrm{~min}$ at $85^{\circ} \mathrm{C}$. Hybridization proceeded at $37^{\circ} \mathrm{C}, 16 \mathrm{~h}$. After hybridization, slides were washed in $0.3 \% \mathrm{NP} 40 / 0.4 \times \mathrm{SSC}$ for $2 \mathrm{~min}$ at $73{ }^{\circ} \mathrm{C}$ followed by $0.1 \% N P 40 / 2 \times \mathrm{SSC}, 2 \mathrm{~min}$ at $20^{\circ} \mathrm{C}$. Slides were mounted with DAPI (DNA counterstaining; Vysis Inc.). Signals were visualized on a fluorescence microscope equipped with filters for DAPI, FITC, rhodamine and Spectrum Aqua excitation and detection.

Hybridization signals were counted according to previously published criteria, pairs that were spaced less than 
the diameter of a signal domain were counted as one chromosome, and pairs that were farther apart than the diameter of a signal domain were counted as two chromosomes (Hopman et al. 1986). We analyzed 100 cells per patient.

\section{Statistical analysis}

The statistical package Statistics/Data Analysis (STATA) was used for statistical analysis. To determine whether the mean number of MLH1 foci differed between groups, we compared the mean MLH1 foci of each individual in the control group with each individual in the KS group via the non-parametric Mann-Whitney test. To determine whether the fidelity of chromosome synapsis differed between groups, we compared the percentage of cells with fully synapsed bivalents in the control group with an individual in the KS group via the Fisher exact test.

\section{Results}

Meiotic division begins with a period of cell division characterized by four distinct stages: leptotene, zygotene, pachytene and diplotene. As shown, DNA replication and sister chromatid condensation begins in the pre-leptotene to leptotene stages (Fig. 1A). Sister chromatids synapse along their length through the formation of the axial/lateral elements that contain SCP2 and SCP3 during zygotene (Fig. 1B). At pachytene, the sister chromatids are fully synapsed and recombination nodules that contain proteins such as MLH1 are visible (Fig. 1C). Finally, at the diplotene stage, homologous chromosomes begin to separate and sites of recombination, the chiasmata, hold the chromosomes together (Fig. 1D). Meiotic division continues to progress in an orderly fashion through meiosis I to meiosis II unless errors in the recombination or chromosomal segregation machinery trigger arrest at either of two well-defined checkpoints (Roeder 1997, Roeder \& Bailis 2000).

In this study, we analyzed testis tissue from two groups of men: Group I was the control group and contained four fertile men with prior vasectomies. All had histologically normal spermatogenesis. Group II contained four individuals with pure, non-mosaic KS; all were azoospermic and completely lacked sperm in their semen. Histologically, the men with KS in Group II varied, especially in contrast to men with normal spermatogenesis. Men in the control group had complete spermatogenesis with numerous spermatogenic cells present from immature spermatogonia to mature spermatids. In contrast, two patients, KS1 and KS2 (KS patient 1 and 2), had well-organized seminiferous tubules with prophase I spermatocytes present. The other two men, KS3 and KS4, had sclerotic seminiferous tubules with only rare spermatogenic cells observed.

We examined immunostained meiocyte spreads from testis biopsies for each of the men in the control and
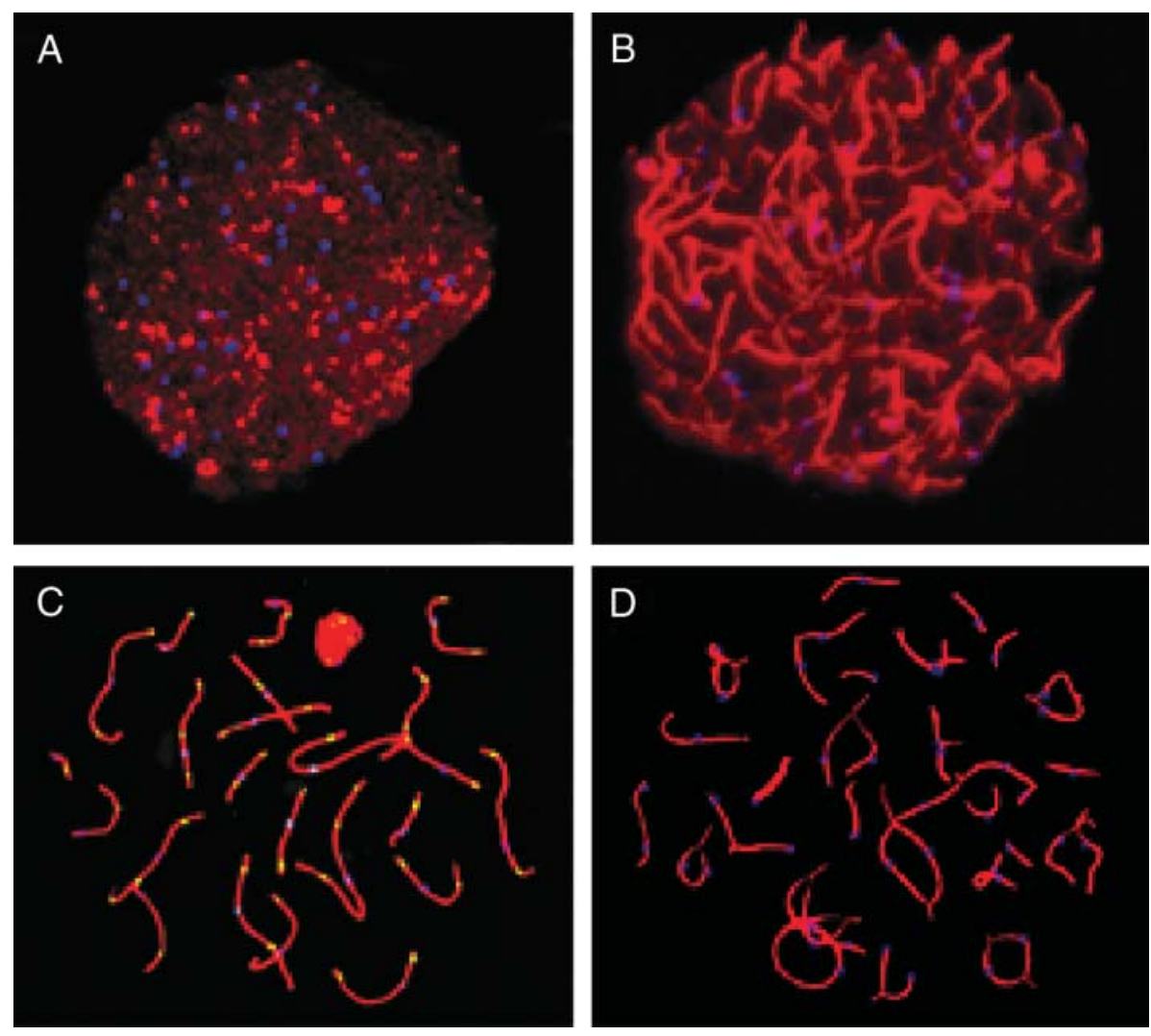

Figure 1 Developmental stages of meiotic prophase I. Shown are cells at the following stages of meiotic prophase I: (A) leptotene; (B) zygotene; (C) pachytene; (D) diplotene. Immunohistochemical analysis of spermatogenic cells was with antisera that recognize SCP3 (red), MLH1 (yellow) and CREST antigens on centromeres (blue). Photographs at $\times 1000$. 

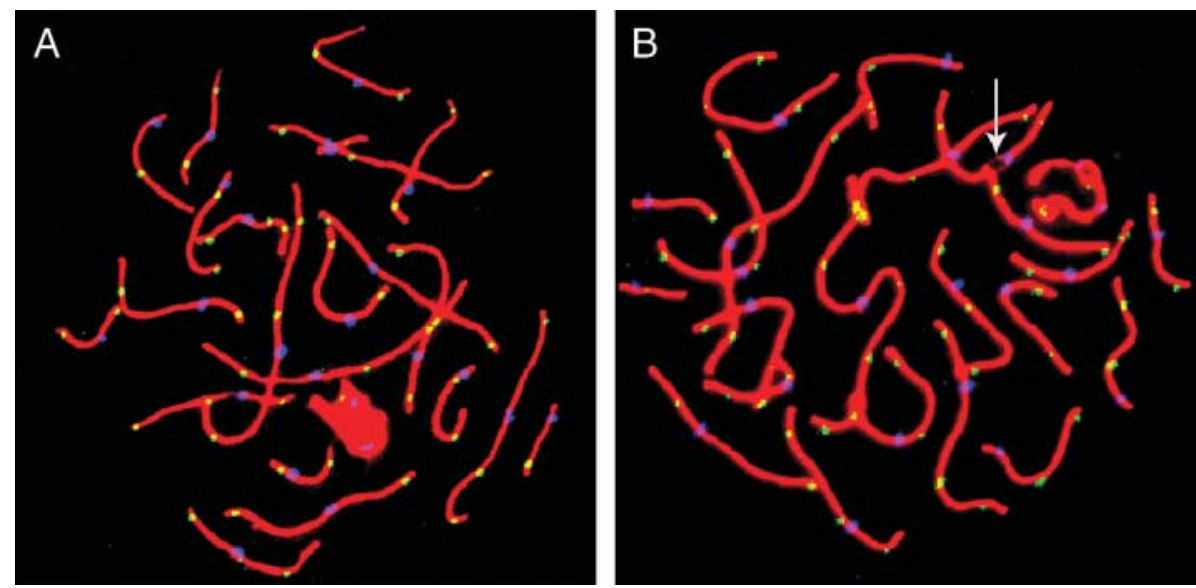

Figure 2 Pachytene spermatocytes from men in the control and KS groups. SCs, red; MLH1 foci, yellow; centromeres, blue. Pachytene spermatocytes from men from (A) the control group and (B) the KS group. Arrow in B indicates incomplete synapsis between two homologous bivalents. Photographs at $\times 1000$.

KS groups (Fig. 2). Since KS3 and KS4 had few or no pachytene cells, assessment of their recombination frequencies was not possible. KS1 and KS2, however, had sufficient numbers of pachytene cells to analyze recombination. Thus, the autosomal recombination frequency and synapsis fidelity was measured as described with antisera that mark the centromere (CREST antisera), sites of meiotic recombination (MLH1 antisera), and SCP3 (Gonsalves et al. 2004). Results indicated that there was no significant difference in autosomal recombination frequencies between these men and controls. Our control group had an overall mean of $44.1 \pm 4.7$ (S.D.) and a range of $42.6 \pm 5.9$ to $45.6 \pm 4.2$ recombination loci per pachytene spermatocyte (Table 1, Fig. 2). Similarly, the men with KS had an overall mean of $46.6 \pm 5.6$ and a range of $45.8 \pm 6.7$ to $46.8 \pm 5.2$ recombination loci per pachytene spermatocyte (Table 1, Fig. 2). In contrast, when we tallied fidelity of chromosomal synapsis (percentage of cells with fully synapsed bivalents), we observed that KS2 had a significantly lower percentage of cells with fully synapsed bivalents compared with men in the control group ( $P<0.0001$ for comparisons with $\mathrm{C} 1$ and $\mathrm{C} 2$ (control patients 1 and 2), $P<0.0007$ for comparison with C4, and $P<0.01$ for comparison with C3).

To analyze pairing of the sex chromosomes, we examined 100 meiotic cells from KS2 and as a control C4. We found that $99 \%$ (99) of meiotic cells were $X Y$ and $1 \%$ (1) of meiotic cells were $X X Y$ in the control, whereas, 47\% (47) of meiotic cells had an XXY karyotype and 53\% (53) had an XY karyotype in the KS individual (Fig. 3).

Finally, we examined outcomes of ART in the men with $\mathrm{KS}$, expecting that those with abundant pachytene spermatocytes would be more likely to produce sperm. Surprisingly, however, in spite of the dramatic differences in histology and differences in SC fidelity, all four men with KS produced rare sperm that were used to fertilize oocytes (Fig. 4). Fertilization occurred with sperm from all four

Table 1 Analysis of recombination and assisted reproduction outcomes for men in the control and Klinefelter syndrome groups. The control group consisted of fertile men who had had vasectomies. The Klinefelter syndrome men consisted of men who were diagnosed with Klinefelter syndrome and were azoospermic (no sperm in the semen). KS2 is the man with significant reductions in synapsis fidelity, as noted by reduced percentage of pachytene cells with fully synapsed bivalents.

\begin{tabular}{|c|c|c|c|c|c|c|c|c|}
\hline \multirow[b]{2}{*}{ Patient } & \multirow[b]{2}{*}{ Age } & \multirow{2}{*}{$\begin{array}{l}\text { No. pachytene } \\
\text { cells analyzed }\end{array}$} & \multicolumn{2}{|c|}{ MLHI foci } & \multirow{2}{*}{$\begin{array}{c}\text { Cells with fully synapsed } \\
\text { bivalents }(\%)\end{array}$} & \multirow{2}{*}{$\begin{array}{l}\text { Sperm } \\
\text { found }\end{array}$} & \multirow{2}{*}{$\begin{array}{l}\text { Embryos } \\
\text { after ICSI }\end{array}$} & \multirow{2}{*}{$\begin{array}{l}\text { Confirmed } \\
\text { pregnancy }\end{array}$} \\
\hline & & & Mean \pm S.D. & Range & & & & \\
\hline \multicolumn{9}{|c|}{ Controls } \\
\hline $\mathrm{C} 1$ & 51 & 62 & $45.6 \pm 4.2$ & $36-55$ & 88.70 & Yes & N/A & - \\
\hline $\mathrm{C} 2$ & 56 & 94 & $44.4 \pm 4.7$ & $32-53$ & 86.20 & Yes & N/A & - \\
\hline $\mathrm{C} 3$ & 46 & 46 & $42.6 \pm 5.9$ & $26-51$ & 80.40 & N/A & N/A & - \\
\hline C4 & 48 & 79 & $43.4 \pm 4.1$ & $35-53$ & 83.60 & Yes & N/A & - \\
\hline \multicolumn{9}{|c|}{ Klinefelter syndrome } \\
\hline KS1 & 27 & 17 & $45.8 \pm 6.7$ & $25-52$ & N/A & Yes & Yes & Yes \\
\hline KS2 & 36 & 63 & $46.8 \pm 5.2$ & $33-57$ & 57.10 & Yes & Yes & Yes \\
\hline KS3 & 26 & NP & N/A & N/A & $\mathrm{N} / \mathrm{A}$ & Yes & Yes & Yes \\
\hline KS4 & 44 & NP & N/A & N/A & N/A & Yes & Yes & NT \\
\hline
\end{tabular}

C, control; ICSI, intracytoplasmic sperm injection; KS, Klinefelter syndrome; NP, not enough pachytene cells to analyze; N/A, not available; NT, no transfer. 

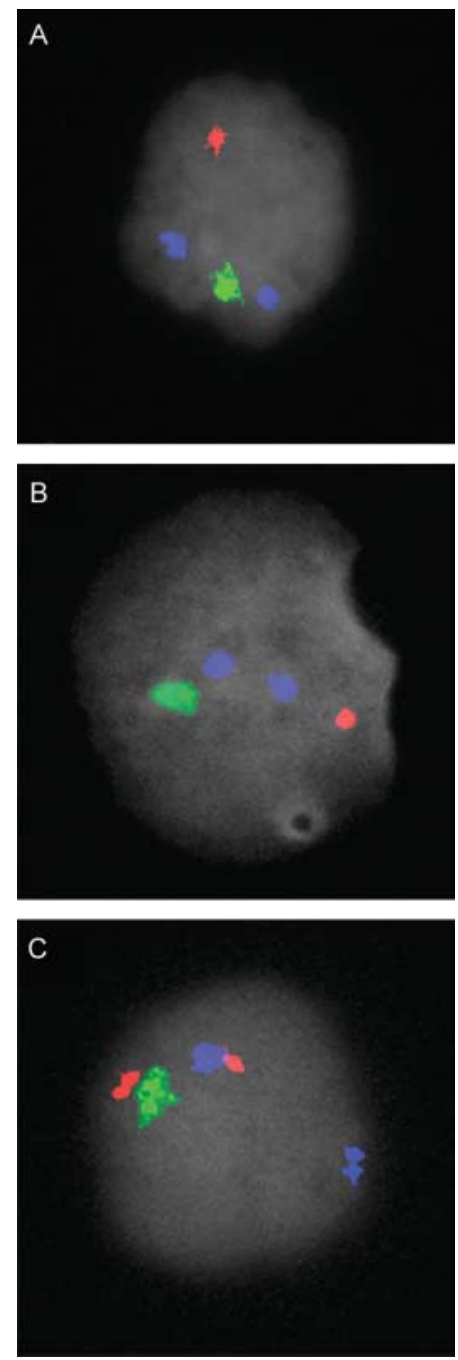

Figure $3 \mathrm{FISH}$ of meiotic cells from men in (A) the control group with a normal $X Y$ karyotype, (B) the KS group with a normal XY karyotype and $(\mathrm{C})$ the KS group with an XXY karyotype. Chromosomes 18, blue; $X$ chromosomes, red; $Y$ chromosomes, green.

men, although embryos were subsequently transferred only in the cases of KS1, KS2 and KS3. Pregnancies resulted in all three cases of embryo transfer and all babies were born without any chromosomal abnormalities, including the case of KS2 where fidelity of synapsis was clearly compromised. Three boys and three girls were born.

\section{Discussion}

Men with KS have increased aneuploidy in their sperm compared with fertile men with normal spermatogenesis (Guttenbach et al. 1997). In model organisms, nondisjunction or errors in meiotic chromosome segregation are associated with absent or reduced levels of recombination as well as with recombination in suboptimal chromosome positions (Hassold \& Hunt 2001).
We hypothesized that men with KS might have altered global recombination frequencies. However, we observed no significant difference in autosomal recombination frequency in this small study. Instead we observed a significant difference in the synapsis fidelity in one man with KS relative to controls. Synapsis, the tight axial association which brings the four chromatids into an intimate alignment and stabilizes the pairing event of chromosomes during prophase of meiosis I, has been shown to be required for meiotic progression in most organisms (Yuan et al. 2000, Libby et al. 2002). A recent report also documented a case of an infertile man with meiotic I arrest due to failure of formation of the SC (Judis et al. 2004). In this individual 46 full-length axial elements were observed, but no evidence of synapsis was seen between homologous chromosomes. Thus, it was concluded that abnormalities in the SC formation may be associated with a proportion of cases of unexplained male infertility (Judis et al. 2004). A second case report identified a man with non-obstructive azoospermia with reduced recombination frequency and discontinuities in the SC (Sun et al. 2004). Here we also report an individual with KS who has SC formation defects. The defect is characterized by regions of incomplete synapsis between bivalents. This phenotype is not as extreme as complete failure to synapse but is intriguing in that it suggests the possibility that abnormalities in synapsis formation might also be associated with infertility and aneuploidy in KS patients. Due to the fact that altered recombination increases the likelihood of aneuploidy, a synapsis defect might be associated with the higher rate of aneuploidy that is seen in sperm from men with KS compared with fertile men.

It is notable that histological phenotypes in men with KS varied widely. Two men had a nearly complete arrest of meiosis, with few sperm found in biopsies and only rare prophase meiotic cells seen in sclerotic somniferous tubules. The other two men had an abundance of prophase meiotic cells seen in an organized seminiferous tubule. This variation in phenotypes, all associated with a $47, \mathrm{XXY}$ genotype, suggests that meiotic checkpoints in these men may vary in response to aneuploidy. Even more notable is that despite these histological differences, sperm were isolated for embryo production in all cases; moreover, in three of four cases, implantation resulted in birth of healthy, chromosomally normal babies. Notably this success was evident even in the case where $47 \%$ of spermatocytes were found to carry the abnormal XXY karyotype.

Unfortunately, although it would be useful to directly compare characteristics of sperm from KS men with characteristics of sperm obtained from other azoospermic men, sperm from men with KS are rare, limiting the feasibility of such a study. Nonetheless, our observations suggest that it would be beneficial to conduct expanded studies of autosomal recombination with a larger population of men who report for ART in order to examine 


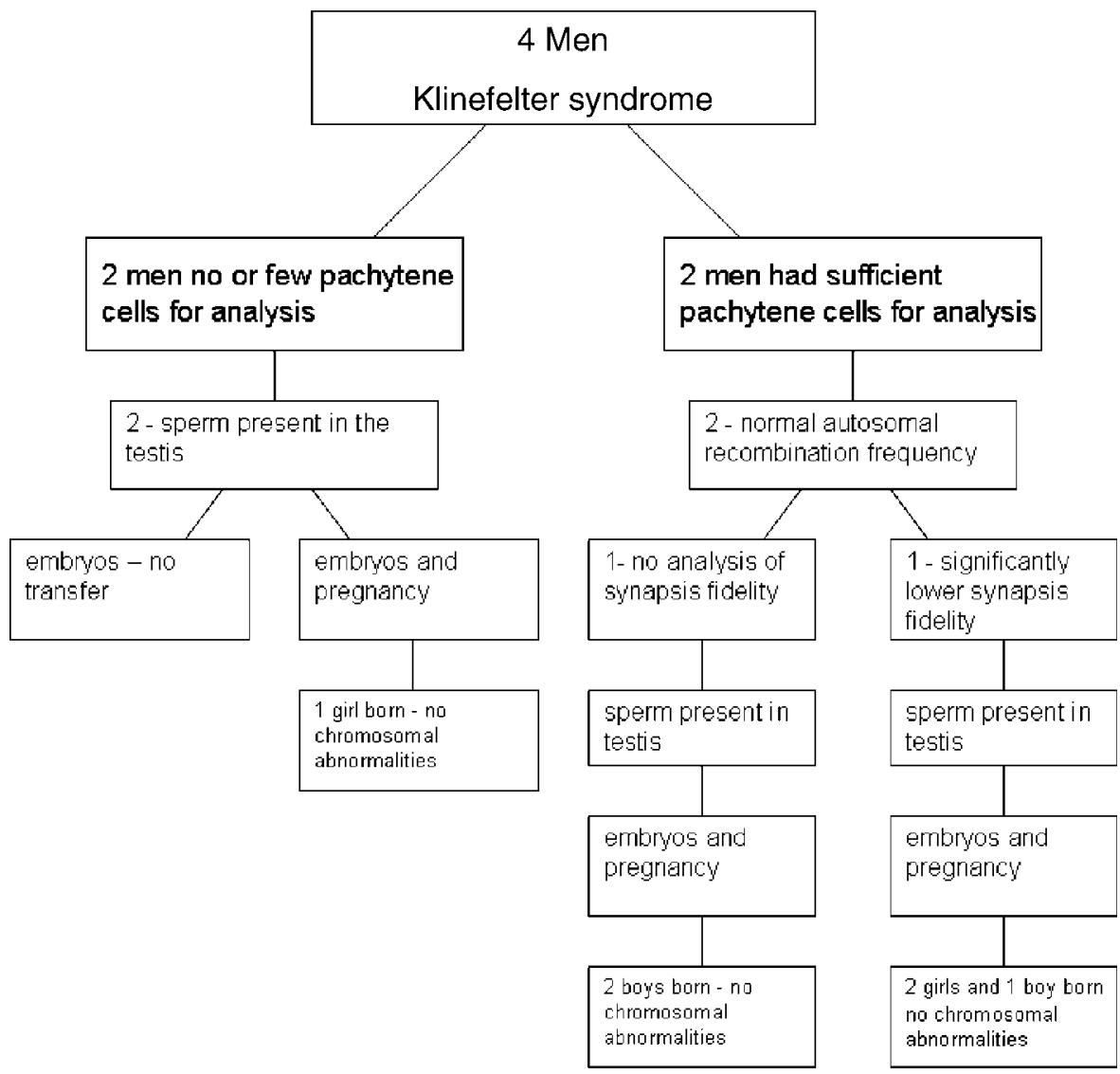

Figure 4 Summary of recombination and synapsis fidelity and outcomes of ART in men with KS. outcomes when sperm with diverse chromosomal disorders are used in ART.

\section{Acknowledgements}

We thank B Brinkley and C Heyting for antibodies, M Abeyta, A Clark, T Hassold, L Judis and $\mathrm{H} N$ Nguyen for technical assistance, and D Hardy, M Hardy and A Mielnik for assistance at the Population Council. This research was supported by grants from the National Institute of General Medical Sciences (RS25GM56847 to J G) and the National Institute of Child Health and Human Development (RO1HD38987 to R A R P). The authors declare that there is no conflict of interest that would prejudice the impartiality of this scientific work.

\section{References}

Aran B, Blanco J, Vidal F, Vendrell JM, Egozcue S, Barri PN et al. 1999 Screening for abnormalities of chromosomes X, Y, and 18 and for diploidy in spermatozoa from infertile men participating in an in vitro fertilization-intracytoplasmic sperm injection program. Fertility and Sterility 72 696-701.

Barlow AL \& Hulten MA 1998 Crossing over analysis at pachytene in man. European Journal of Human Genetics 6 350-358.

Estop AM, Munne S, Cieply KM, Vandermark KK, Lamb AN \& Fisch H 1998 Meiotic products of a Klinefelter 47, XXY male as determined by sperm fluorescence in situ hybridization analysis. Human Reproduction 13 124-127.

Foresta C, Galeazzi C, Bettella A, Stella M \& Scandellari C 1998 High incidence of sperm sex chromosomes aneuploidies in two patients with Klinefelter's syndrome. Journal of Clinical and Endocrinological Metabolism 83 203-205.

Gonsalves J, Sun F, Schlegel PN, Turek PJ, Hopps CV \& Greene C et al. 2004 Defective recombination in infertile men. Human Molecular Genetics 13 2875-2883.

Guttenbach M, Martinez-Exposito MJ, Michelmann HW, Engel W \& Schmid M 1997a Incidence of diploid and disomic sperm nuclei in 45 infertile men. Human Reproduction 12 468-473.

Guttenbach M, Michelmann HW, Hinney B, Engel W \& Schmid M 1997b Segregation of sex chromosomes into sperm nuclei in a man with 47,XXY Klinefelter's karyotype: a FISH analysis. Human Genetics 99 474-477.

Hassold T \& Hunt P 2001 To err (meiotically) is human: the genesis of human aneuploidy. Nature Reviews. Genetics 2 280-291.

Hennebicq S, Pelletier R, Bergues U \& Rousseaux S 2001 Risk of trisomy 21 in offspring of patients with Klinefelter's syndrome. Lancet $3572104-2105$.

Hopman AH, Wiegant J, Raap AK, Landegent JE, van der Ploeg M \& van Duijn P 1986 Bi-color detection of two target DNAs by non-radioactive in situ hybridization. Histochemistry $851-4$.

Judis L, Chan ER, Schwartz S, Seftel A \& Hassold T 2004 Meiosis I arrest and azoospermia in an infertile male explained by failure of formation of a component of the synaptonemal complex. Fertility and Sterility $\mathbf{8 1} 205-209$.

Kruse R, Guttenbach M, Schartmann B, Schubert R, van der Ven $\mathbf{H}$, Schmid M et al. 1998 Genetic counseling in a patient with $\mathrm{XXY} / \mathrm{XXXY/XY}$ mosaic Klinefelter's syndrome: estimate of sex chromosome aberrations in sperm before intracytoplasmic sperm injection. Fertility and Sterility $69482-485$.

Levron J, Aviram-Goldring A, Madgar I, Raviv G, Barkai G \& Dor J 2001 Studies on sperm chromosomes in patients with severe male factor infertility undergoing assisted reproductive technology 
treatment. Molecular and Cellular Endocrinology 183 (Suppl 1) S23-S28.

Libby BJ, De La Fuente R, O'Brien MJ, Wigglesworth K, Cobb J, Inselman A, Eaker S, Mandel MA, Eppig JJ \& Schimenti JC 2002 The mouse meiotic mutation mei1 disrupts chromosome synapsis with sexually dimorphic consequences for meiotic progression. Developmental Biology 242 174-187.

Lim AS, Fong Y \& Yu SL 1999 Estimates of sperm sex chromosome disomy and diploidy rates in a $47, \mathrm{XXY} / 46, \mathrm{XY}$ mosaic Klinefelter patient. Human Genetics 104 405-409.

Lue Y, Rao PN, Sinha Hikim AP, Im M, Salameh WA, Yen PH et al. 2001 XXY male mice: an experimental model for Klinefelter syndrome. Endocrinology 142 1461-1470.

Lynn A, Koehler KE, Judis L, Chan ER, Cherry JP, Schwartz S et al. 2002 Covariation of synaptonemal complex length and mammalian meiotic exchange rates. Science $2962222-2225$.

Martini E, Geraedts JP, Liebaers I, Land JA, Capitanio GL, Ramaekers FC et al. 1996 Constitution of semen samples from XYY and XXY males as analysed by in situ hybridization. Human Reproduction 11 1638-1643.

Moosani N, Pattinson HA, Carter MD, Cox DM, Rademaker AW \& Martin RH 1995 Chromosomal analysis of sperm from men with idiopathic infertility using sperm karyotyping and fluorescence in situ hybridization. Fertility and Sterility 64 811-817.

Morel F, Bernicot I, Herry A, Le Bris MJ, Amice V \& De Braekeleer M 2003 An increased incidence of autosomal aneuploidies in spermatozoa from a patient with Klinefelter's syndrome. Fertility and Sterility 79 (Suppl 3) 1644-1646.

Mroz K, Hassold TJ, Hunt PA 1999 Meiotic aneuploidy in the XXY mouse: evidence that a compromised testicular environment increases the incidence of meiotic errors. Human Reproduction $\mathbf{1 4}$ $1151-1156$

Okada H, Fujioka H, Tatsumi N, Kanzaki M, Okuda Y, Fujisawa M, Hazama M, Matsumoto O, Gohji K, Arakawa S \& Kamidono S
1999 Klinefelter's syndrome in the male infertility clinic. Human Reproduction 14 946-952.

Rives N, Joly G, Machy A, Simeon N, Leclerc P \& Mace B 2000 Assessment of sex chromosome aneuploidy in sperm nuclei from 47, XXY and 46,XY/47, XXY males: comparison with fertile and infertile males with normal karyotype. Molecular Human Reproduction 6 107-112.

Roeder GS 1997 Meiotic chromosomes: it takes two to tango. Genes and Development 11 2600-2621.

Roeder GS \& Bailis JM 2000 The pachytene checkpoint. Trends in Genetics 16 395-403.

Simpson JL, de la Cruz F, Swerdloff RS, Samango-Sprouse C, Skakkebaek NE, Graham JMJ, Hassold T, Aglstock M, Meyer-Bahlburg HF, Willard HF et al. 2003 Klinefelter syndrome: expanding the phenotype and identifying new research directions. Genetic Medicine 5 460-468.

Smyth CM \& Bremner WJ 1998 Klinefelter syndrome. Archives of Internal Medicine 158 1309-1314.

Sun F, Kozak G, Scott S, Trpkov K, Ko E, Mikhaail-Philips M et al. 2004 Meiotic defects in a man with non-obstructive azoospermia: case report. Human Reproduction 19 1770-1773.

Thomas NS \& Hassold TJ 2003 Aberrant recombination and the origin of Klinefelter syndrome. Human Reproduction Update $\mathbf{9}$ 309-317.

Yuan L, Liu JG, Zhao J, Brundell E, Daneholt B \& Hoog C 2000 The murine SCP3 gene is required for synaptonemal complex assembly, chromosome synapsis, and male fertility. Molecular Cell 5 73-83.

Received 4 January 2005

First decision 21 February 2005

Revised manuscript received 2 May 2005

Accepted 23 May 2005 